\title{
Resilient employees are creative employees, when the workplace forces them to be
}

\author{
Dirk De Clercq ${ }^{1}$ (D) । Renato Pereira ${ }^{2,3}$
}

\author{
${ }^{1}$ Goodman School of Business, Brock \\ University, St. Catharines, Ontario, Canada \\ ${ }^{2}$ OBSERVARE Research Centre, Lisbon, \\ Portugal \\ ${ }^{3}$ ISCTE Business School, Instituto Universitário \\ de Lisboa, Lisbon, Portugal \\ Correspondence \\ Dirk De Clercq, Goodman School of Business, \\ Brock University, St. Catharines, Ontario L2S \\ 3A1, Canada. \\ Email: ddeclercq@brocku.ca
}

\begin{abstract}
With a basis in conservation of resources theory, this article considers the connection between employees' resilience and disruptive creative behaviour-conceptualized herein as the extent to which they generate radically new ideas for organizational improvement-as well as how this connection might be invigorated by resourcedraining work conditions that stem from excessive workloads and unfavourable decision-making processes. Data collected through a survey administered to employees in an organization that operates in the distribution sector reveal that employees' resilience levels spur their disruptive creative behaviour, and this process is more prominent among employees who believe they have insufficient time to complete their work tasks (i.e., suffer from high work overload) and operate in organizational climates marked by high rigidity or dysfunctional politics. The findings accordingly inform organizational practitioners that the allocation of employees' personal resource bases to disruptive creative behaviours might be particularly useful among employees who face substantial adversity in their organizational functioning.
\end{abstract}

\section{1 | INTRODUCTION}

Employees' generation of radically new ideas that disrupt the status quo can add to their organization's success, to the extent that these ideas suggest new work practices that help resolve organizational shortcomings or failures (Bos-Nehles, Bondarouk, \& Nijenhuis, 2017; Frishammar, Dahlskog, Krumlinde, \& Yazgan, 2016; Naranjo-Valencia, Jimenez-Jimenez, \& Sanz-Valle, 2017; Oldham \& Cummings, 1996). These disruptive, creative behaviours may be useful for not just the organization's competitive standing but also their performers, in that creative employees often enjoy more favourable performance evaluations (Gong, Huang, \& Farh, 2009) and enhanced career prospects (Seibert, Kraimer, \& Crant, 2001). Creative behaviours also can add to employees' satisfaction levels and generate a general sense of meaningfulness, especially if they are able to find adequate remedies for poor processes and practices in their work environment (Kim, Hon, \& Crant, 2009) and gain insights into future activities (Parboteeah, Hoegl, \& Muethel, 2015).

Yet the development of radically new ideas also can be challenging, in that these activities consume substantial energy (Bos-Nehles et al., 2017; Deichmann \& van den Ende, 2014). This challenge is exacerbated when other organizational members express doubts about the value of disruptive ideas (Milliken, Morrison, \& Hewlin, 2003; van Dijk \& van Dick, 2009) or even actively resist them, because they feel threatened by the anticipated organizational changes (Buchanan \& Badham, 1999; Zhou \& George, 2001). Persistent efforts to develop radically new ideas also might undermine employees' reputation in the organization, particularly if their ideas are in conflict with existing organizational procedures and values (Yuan \& Woodman, 2010). Because they need considerable energy to withstand such criticism or resistance, it is critical to understand how employees' personal energy bases, as informed by their individual characteristics, may spur the likelihood of their creative behaviours.

The central premise of this study is that to enable disruptive creative behaviours, and overcome possible resistance to such behaviours, a critical factor is employees' resilience levels. Resilience is an energygenerating personal resource that reflects employees' ability to recover from challenging work situations and associated propensity to learn from these experiences (Luthans, 2002; Stephens, Heaphy, Carmeli, Spreitzer, \& Dutton, 2013). Employees equipped with more resilience tend to bounce back from setbacks at work, see workrelated adversity as an opportunity to grow, and get better at their 
work because of their ability to learn from their mistakes (Youssef \& Luthans, 2007). Previous research has not explicitly investigated how employees' resilience levels might enhance the likelihood that they generate radically new ideas for organizational improvement. This oversight is notable, because it limits organizations' understanding of how an important energy-enhancing personal factor that helps employees master and learn from workplace adversity might generate the stamina they need to introduce disruptive solutions to organizational problems-even if those solutions may appear upsetting or threatening to other members (Milliken et al., 2003; Morrison, 2011; Sutton \& Hargadon, 1996).

In response, this research seeks to detail how and when employees' resilience might stimulate their propensity to undertake disruptive creative behaviours. Our theoretical arguments are anchored in conservation of resources (COR) theory, according to which employees' work behaviours are largely driven by their search to achieve resource gains and avoid resource losses (Hobfoll, 1989, 2001). First, employees have a greater tendency to undertake productive work activities, such as creativity, to the extent that they are able to leverage valuable personal resources to generate resource gains through these activities (Hobfoll, 2001). We argue that employees' resilience represents such a personal resource, in that it provides them with discretionary energy from which they can draw to undertake disruptive work behaviours that might add to their organization's well-being, as well as their own professional success (Caniëls \& Baaten, 2019; Meneghel, Salanova, \& Martínez, 2016; Wolfson \& Mulqueen, 2016). Their resilience and associated desire to learn from difficult work situations also might make the generation of radically new ideas more personally fulfilling and satisfying (Cho, Park, \& Dahlgaard-Park, 2017; Meneghel, Borgogni, Miraglia, Salanova, \& Martínez, 2016), despite any scepticism or even overt criticism with which these ideas might be received by other members (Deichmann \& van den Ende, 2014).

Second, COR theory suggests that the application of discretionary personal energy to resource-generating work behaviours is particularly useful to the extent that employees operate in unfavourable work environments that pose a threat of future resource losses (Hobfoll \& Shirom, 2000). Leveraging a personal resource such as resilience into disruptive creative behaviours should have greater anticipated value to the extent that adverse work conditions make such leveraging efforts a useful means to cope with the adversity (De Clercq \& Belausteguigoitia, 2017b). In accordance with this logic, we consider how three facets of workplace adversity-one reflecting the nature of the work task environment (i.e., work overload) and two that speak to the nature of organizational decision making (i.e., organizational rigidity and organizational politics)-might invigorate the positive relationship between employees' resilience and disruptive creative behaviour. That is, the application of their personal energy, derived from resilience, to the generation of radically new ideas should be more likely when employees believe (1) they face excessive time constraints in their work tasks (Altaf \& Awan, 2011), (2) their organization is not open to change (Scott \& Bruce, 1994), and (3) a self-serving organizational climate exists, in which people focus on their personal interests irrespective of the consequences for others (Abbas, Raja, Darr, \& Bouckenooghe, 2014).

\section{1 | Contributions}

We seek to extend prior research by considering a hitherto unexplored driver of employees' generation of disruptive ideas (their resilience) and detail when this energy-generating personal resource is more likely to stimulate such behaviours. Prior research into the influences of employees' personal characteristics on creativity tends to focus on enabling factors such as the Big Five personality traits of openness and conscientiousness (George \& Zhou, 2001), creative self-efficacy (Tierney \& Farmer, 2002), role identity (Farmer, Tierney, \& Kung-Mclntyre, 2003), or thriving (Carmeli \& Spreitzer, 2009). Further, Sweetman, Luthans, Avey, and Luthans (2011) note that the four components of psychological capital (self-efficacy, hope, optimism and resilience) relate positively to creative performance (number of ideas produced during brainstorming sessions) and that psychological capital, as a second-order construct, exhibits an even stronger relationship with such performance.

We complement such findings by arguing that the great resistance and even sabotage that employees might encounter when suggesting radically new ideas for organizational improvement (Deichmann \& van den Ende, 2014; Frishammar et al., 2016) means that for this work behaviour, the specific resource of resilience might be a particularly important enabler. Employees' resilience can spur beneficial behavioural outcomes such as proactive work behaviour (Caniëls \& Baaten, 2019) and extra-role behaviour (Meneghel et al., 2016), but we know of no research that investigates its influence on the development of disruptive ideas that upset the organizational status quo. Moreover, our focus on the connection between employees' resilience and creativity complements and extends research that has investigated this connection at the organizational level (Richtnér \& Löfsten, 2014). Notably, by considering how individual employees' resilience levels may spur their development of disruptive ideas, we address how this personal resource influences daily work activities, such as creativity, rather than taking a restrictive view of its role solely in response to extreme organization-level crises (Stokes et al., 2018).

We also explicate that the anticipated value of leveraging resilience to engage in disruptive creative behaviours is greater when employees face resource-draining circumstances, due the presence of excessive time pressures (Avery, Tonidandel, Volpone, \& Raghuram, 2010) or organizational decision making marked by a lack of flexibility (Fischer et al., 2014) or behind-the-scenes decision dynamics (Chang, Rosen, \& Levy, 2009). Together, these three contingency factors offer a novel, parsimonious, yet comprehensive perspective on how employees' exposure to unfavourable, resource-draining work circumstances may trigger their motivation to leverage the personal resource of resilience, in the form of disruptive creative behaviours (Hobfoll \& Shirom, 2000). The common thread that runs through these contingencies is that they each pose a significant threat of future resource losses for employees, through a reduction in the quality of their current or future organizational functioning. 
An opposing logic would be that employees are more inclined to leverage their resilience toward creative behaviours when they are surrounded by supportive or protective organizational environments; we argue that this logic instead is dominated by the perceived usefulness of leveraging valuable personal resources, such as resilience, toward resource-generating work behaviours in the presence of workplace adversity (De Clercq \& Belausteguigoitia, 2017b). To the extent that employees believe their organizational environment undermines the quality of their job functioning, they should be especially motivated to apply discretionary energy, derived from their personal resource of resilience, to the generation of radical new ideas for organizational improvement (Quinn, Spreitzer, \& Lam, 2012). This energy application appears particularly necessary in such a scenario and thus can generate even more resource gains (Hobfoll \& Shirom, 2000).

With this focus on how the anticipated value of employees' resilience levels for their disruptive creative behaviours might depend on the presence of the three contingencies, we also add to previous studies that tend to focus on the direct negative effects of employees' exposure to excessive workloads (Chen, Chang, \& Chang, 2015), organizational climates that resist change (Scott \& Bruce, 1994) or dysfunctional political games (Jam, Donia, Raja, \& Ling, 2017) on their positive work behaviours. Instead, this study aims to help organizations identify the boundary conditions at which employees might be more keen to engage in activities that offer novel solutions to organizational issues (Bardoel, Pettit, De Cieri, \& McMillan, 2014; King, Newman, \& Luthans, 2016; Wolfson \& Mulqueen, 2016). The proposed invigorating effects of the three moderators provide the additional insight that organizational improvements that might arise from disruptive creative behaviours undertaken by resilient employees can help resolve organizational challenges that result from resource-depleting work situations, marked by heavy workloads and poor decision-making practices (Hobfoll \& Shirom, 2000; Linnenluecke, 2017).

We summarize the proposed conceptual framework and its constitutive hypotheses in Figure 1. The baseline hypothesis suggests a positive relationship between employees' resilience and disruptive creative behaviour. We anticipate that this process is triggered or invigorated by three sources of workplace adversity: work overload, organizational rigidity and organizational politics.

\section{2 | HYPOTHESES}

\section{1 | Resilience and disruptive creative behaviour}

We hypothesize a positive relationship between employees' resilience and their propensity to generate radically new ideas for organizational improvement. Their resilience is a personal resource that defines the extent to which employees successfully bounce back and learn from negative situations (Bardoel et al., 2014; Luthans, 2002). This resource is useful in that it can help counter the resistance that employees tend to experience when other members feel upset or threatened by the changes that might arise with the implementation of radically new ideas (Wolfson \& Mulqueen, 2016; Youssef \& Luthans, 2007). For example, other members might worry that their current privileges will be undermined if the proposed ideas highlight their shortcomings (Liang, Farh, \& Farh, 2012; Yuan \& Woodman, 2010), so a personal resource such as resilience can be instrumental for idea proponents to deal with the stress of having to overcome resistance to their ideas (Conley, Clark, Vande Griek, \& Mancini, 2016; Zhou \& George, 2001). In turn, employees' ability to find effective ways to handle difficult work situations, as informed by their resilience, should diminish the chances that they will halt their disruptive creative efforts, regardless of whether those efforts are welcomed (Caniëls \& Baaten, 2019). Further, this personal resource may increase the motivation of resilient employees to introduce their disruptive ideas, because they expect that leveraging their personal energy into creative efforts will generate resource gains, as a positive contribution to organizational effectiveness or by generating a sense of personal meaningfulness (Cho et al., 2017; Wang, Li, \& Li, 2017).

In contrast, employees who do not easily bounce back from setbacks may not have the energy required to come up with disruptive

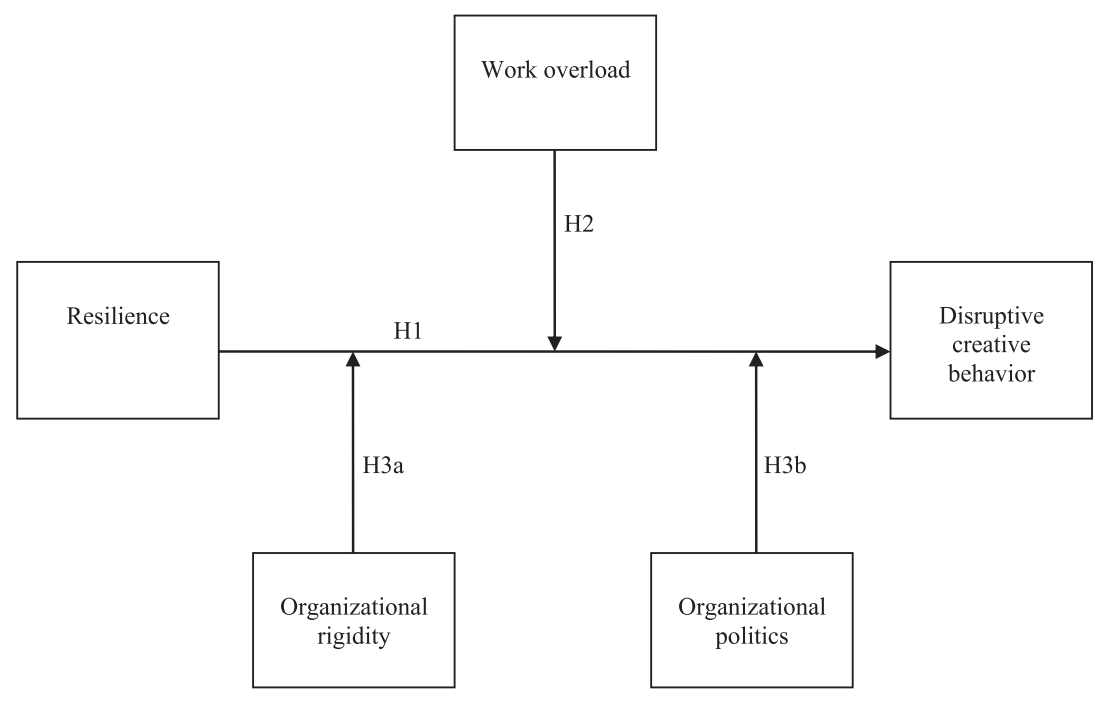


ideas (Deichmann \& van den Ende, 2014). These employees have less ability to deal effectively with negative reactions to their efforts, which also thwarts their motivation to allocate significant energy to them (Bardoel et al., 2014; Luthans, 2002; Wolfson \& Mulqueen, 2016). They may opt to dedicate their time and energy to less controversial activities, rather than worry about whether other members will recognize the value of their ideas (van Dijk \& van Dick, 2009). That is, employees with less resilience may be less likely to believe that they can convince their peers of the value of radically new ideas, because they lack the energy to deal with negative responses to these ideas (Conley et al., 2016).

Employees who exhibit high levels of resilience also may regard the generation of radically new ideas and the resulting resistance as opportunities to learn (Luthans, 2002; Stephens et al., 2013). That is, the learning motivation associated with higher resilience levels might stimulate employees to develop insights about how to protect against possible negative reactions by other organizational members (Masten, 2001; Milliken et al., 2003). Similarly, the possibility of enhanced learning about how to deal with peer resistance may stimulate disruptive creative behaviours, because resilient employees regard this resistance as a positive challenge and a means for personal growth and development (Meneghel, Borgogni, et al., 2016; Youssef \& Luthans, 2007). In this sense, employees' resilience may spur their creation of radically new ideas for organizational improvement, because they derive personal joy from undertaking disruptive activities. In contrast, employees equipped with low resilience are less likely to experience a sense of personal fulfilment, even if they convince organizational peers of the value of their radically new ideas (King et al., 2016; Luthans, 2002), so they are less motivated to invest time in such energy-consuming activities.

Hypothesis 1 . There is a positive relationship between employees' resilience and their disruptive creative behaviour.

\section{2 | Moderating role of work overload}

Excessive workloads represent a resource-draining work condition, because employees experience significant stress if they lack sufficient time to complete their job tasks (Altaf \& Awan, 2011; Pooja, De Clercq, \& Belausteguigoitia, 2016). According to COR theory, the anticipated usefulness of a personal resource, such as resilience, for stimulating disruptive creative behaviours depends on the extent to which employees must cope with adverse, resource-draining work circumstances (Hobfoll, 2001). When employees feel overburdened by unrealistic deadlines, they worry about future resource losses, due to their inability to meet their formal job requirements (Paillé, 2011; Russ-Eft, 2001). In this case, employees who can cope well with and perceive work-related setbacks as opportunities to learn should be especially motivated to leverage their personal energy to generate radically new ideas for organizational improvement, because the associated solutions (i.e., resource gains) help them counter resource losses (Hobfoll \& Shirom, 2000; Meneghel, Borgogni, et al., 2016). Thus, consistent with COR logic, the incremental value of their resilience for creating disruptive ideas for organizational improvement should be higher when employees encounter significant problems with the pace of work and are not sure how to deal with the resulting backlogs (Avery et al., 2010).

Similarly, the allocation of personal energy to the creation of radically new ideas may be helpful for changing an adverse situation, marked by excessive workloads (Naranjo-Valencia et al., 2017; Seeck \& Diehl, 2017). For example, concerns that they have to work fast to meet overly tight deadlines may spur employees to leverage their resilience to find completely new work processes that eliminate this adverse work situation (Russ-Eft, 2001). Conversely, if employees do not feel constrained by the pace of work or time pressures, they can meet their job requirements without having to draw from their resilience or find creative solutions (Altaf \& Awan, 2011; Caniëls \& Baaten, 2019), so the incremental value of resilience diminishes. In the absence of excessive workloads, employees should experience a lower need to leverage their personal resource of resilience in active attempts to find radical solutions to a challenging work environment (Hobfoll \& Shirom, 2000), so the translation of resilience into enhanced disruptive creative behaviour is less likely.

Hypothesis 2. The positive relationship between employees' resilience and their creative behaviour is moderated by their perceptions of work overload, such that the relationship is stronger at higher levels of work overload.

\section{3 | Moderating role of unfavourable organizational decision making}

The value of resilience for stimulating disruptive creative behaviours also may become more prominent if the organizational decisionmaking climate threatens the quality of their organizational functioning. We consider two manifestations of negative decision-making contexts: (1) organizational rigidity, or an absence of organizational support for personal initiative (Fischer et al., 2014), and (2) organizational politics, or the extent to which organizational decision making is marked by favouritism and self-serving motives (Kacmar \& Baron, 1999). When the organizational climate is characterized by such negative dynamics, the threat of future resource losses looms large for employees, because it undermines their ability to meet their job requirements (Abbas et al., 2014; Scott \& Bruce, 1994). Resilient employees should be keen to apply their personal energy to find radically new organizational improvements in these scenarios, because the associated solutions and resource gains can compensate for the resource losses caused by inadequate decision-making processes (Hobfoll \& Shirom, 2000; King et al., 2016). In particular, the usefulness of resilience for generating radically new ideas should increase to the extent that decision making threatens critical resource losses.

First, the incremental contribution of resilience to disruptive creative behaviours should be greater when the organizational climate impedes change (Acikgoz \& Gunsel, 2016; Scott \& Bruce, 1994). 
Employees who believe their organization lacks the flexibility and openness to embrace change will identify strong value in leveraging their discretionary personal energy, derived from their resilience, into disruptive activities that could lower or remove this organizational impediment to their ability to improve their job situation (Cho et al., 2017; De Clercq, Castañer, \& Belausteguigoitia, 2011). For example, if employees feel disheartened by rigid organizational procedures that prevent them from taking personal initiative in performing their jobs, they may feel strongly motivated to use their resilience proactively to suggest radically new procedures for both the means and ends of their job tasks (Bardoel et al., 2014; Caniëls \& Baaten, 2019). Without such organizational rigidity, the personal resource of resilience may have less incremental value in terms of pinpointing problem areas and suggesting radically novel solutions (Hobfoll, 2001).

Second, the anticipated usefulness of leveraging resilience as disruptive creative behaviour should increase to the extent that employees believe their work environment is marked by favouritism or hidden agendas (Kacmar \& Baron, 1999). The more political the organizational climate is-as reflected, for example, in organizational members' propensity to conceal certain information to pursue their own interests (Abbas et al., 2014; Boehlke, 2008; Hochwarter, Kacmar, Perrewé, \& Johnson, 2003)-the more useful it may seem for resilient employees to leverage their personal energy in the form of radically novel ideas to create an organizational climate with more transparent decision-making processes. Notably, employees' belief that people in the organization work behind the scenes to pursue their own personal interests likely spurs their fear that they cannot meet their own job obligations (Crawford, LePine, \& Rich, 2010), so resilient employees should be particularly keen to apply their personal energy to disruptive, creative activities that suggest a way to avoid this resource-draining work situation (Hobfoll, 2001). Conversely, if organizational decision making does not appear driven by self-serving behaviours, employees may have more optimistic impressions of their job situation (Chang et al., 2009), which subdue the perceived need to leverage their resilience in disruptive, creative efforts.

Hypothesis 3. The positive relationship between employees' resilience and disruptive creative behaviour is moderated by their perceptions of (a) organizational rigidity and (b) organizational politics, such that the relationship is stronger when they believe that the organizational climate is marked by higher levels of rigidity or politics.

\section{3 | RESEARCH METHOD}

\subsection{Sample and data collection}

We collected data from employees who work in a large organization operating in the distribution sector in Angola. By focusing on a single organization, we sought to minimize the risk of unobserved differences in employees' disruptive creative efforts due to the internal organizational culture or external competition. Further, the significant competition that this organization faces, in that it competes with a multitude of domestic and international players, and the substantial public attention it receives due to its substantial contributions to Angola's economy means that it faces significant pressures on its internal functioning and decision making. This empirical context accordingly is highly relevant for investigating the allocation of employees' discretionary personal energy levels to disruptive creative behaviours, as well as the roles of different internal organizational conditions with respect to the work task environment and organizational decision making in this process-conditions that might be negatively affected by the stringent competitive pressures in the organization's external market.

The data were collected with a survey instrument administered among a random sample of 440 employees. The survey was in Portuguese, developed using the well-established translation and backtranslation procedure (Brislin, Lonner, \& Thorndike, 1973), such that the questions were prepared in English, translated into Portuguese by a bilingual translator, and then back-translated into English by another bilingual translator. Any differences between the two English versions informed the final version of the Portuguese survey. To reduce the risk of social desirability bias, the cover letters that accompanied the survey ensured participants of complete confidentiality and explained that their participation was entirely voluntary and that they could withdraw at any time. Furthermore, it emphasized that the research goal was to detect general patterns in the aggregate data, instead of singling out individual-level data; noted that there were no correct or incorrect responses and that varied responses across participants were normal; and highlighted the importance of answering the questions as honestly as possible. These measures help reduce concerns about social desirability bias (Spector, 2006). We received 330 responses, which represents a response rate of 75 per cent. Among the respondents, 44 per cent were women, and they had worked for the organization for an average of 17 years.

\section{2 | Measures}

The measures of the five focal constructs come from previously validated scales and use seven-point Likert scales, ranging from 1 ("strongly disagree") to 7 ("strongly agree").

\subsection{1 | Disruptive creative behaviour}

We assessed employees' engagement in disruptive creative behaviour with a three-item scale based on previous research (De Clercq, Rahman, \& Belausteguigoitia, 2017; Janssen, 2001). In light of our focus on the radical character of this behaviour, we adapted the wording of the original items, such that they captured the extent to which employees come up with ideas or solutions that strongly deviate from the status quo, instead of being just new ideas or solutions. The items were "I often create radically new ideas for organizational improvement", "I often generate disruptive solutions to organizational problems", and "I often develop completely new working methods or 
practices that add to organizational effectiveness" (Cronbach's alpha $=.85$ ). Although supervisor-provided ratings can mitigate worries about common method bias, the use of self-reported measures of creativity is common (Kaufman \& Baer, 2004; Shalley, Gilson, \& Blum, 2009; Unsworth \& Mason, 2016) and even might be preferable, because other-rated measures often underestimate the total range of creative behaviours in which employees engage (Zhou, Shin, \& Cannella, 2008). Similarly, our reliance on self-rated creative behaviour, conceptualized to capture the generation of radically new ideas, reflects the argument that self-reported measures provide better assessments of work activities that could be controversial and upsetting, because employees tend to hide them from others (De Clercq et al., 2011; Jones, 2009). Conway and Lance (2010) also affirm that when self-reports are appropriate, concerns about common method bias are significantly diminished.

\subsection{2 | Resilience}

We measured employees' resilience levels with a five-item scale drawn from previous studies (Stephens et al., 2013). Three example items were "I bounce back when I confront setbacks at work", "I see challenges as an opportunity to learn" and "Dealing with difficult colleagues or situations enables me to grow" (Cronbach's alpha $=.76$ ).

\subsection{3 | Work overload}

The extent to which employees experience extensive time pressures during the execution of their job tasks was measured with a four-item scale of work overload, consistent with prior research (Janssen, 2001; Pooja et al., 2016). Two example items were "I often have to work too fast" and "I often have problems with the pace of work" (Cronbach's alpha $=.78)$.

\subsection{4 | Organizational rigidity}

We measured employees' beliefs that organizational decision-making processes stifle change with a four-item reverse-coded scale of organizational support for innovation (Scott \& Bruce, 1994). For example, employees were asked to assess the following items: "My company is responsive to change" and "Innovation is encouraged in my company" (Cronbach's alpha $=.89$ ).

\subsection{5 | Organizational politics}

Employees' belief that organizational decision making is characterized by favouritism and self-serving efforts was measured with a four-item scale of perceived organizational politics (De Clercq \& Belausteguigoitia, 2017a; Hochwarter et al., 2003). Sample items included "People are working behind the scenes to ensure that they get their piece of the pie" and "People do what's best for them, not what's best for the organization" (Cronbach's alpha $=.81$ ).

\subsection{6 | Control variables}

We controlled for gender, because this personal characteristic might have an impact on the likelihood that employees engage in creative behaviours (Baer \& Kaufman, 2008). We also controlled for employees' organizational tenure-people who have worked for the organization for longer may feel more confident about the value of their radically new ideas and thus be less fearful that their ideas will be resisted by other members (Gong et al., 2009).

We checked the validity of the five focal constructs with a confirmatory factor analysis of the five-factor measurement model (Anderson \& Gerbing, 1988). Its fit was good: $\chi^{2}{ }_{(176)}=404.72$, confirmatory fit index $=.91$, incremental fit index $=.92$, and root mean squared error of approximation $=.06$. The significant factor loadings ( $t$ > 2.0; Gerbing \& Anderson, 1988) for each item on its respective constructs indicated the presence of convergent validity. Furthermore, we found evidence of discriminant validity among the constructs, because for each pairing of the five focal constructs, the fit of a constrained model in which their correlation was set equal to 1 was significantly worse $\left(\Delta x^{2}{ }_{(1)}>3.84, p<.05\right)$ than the fit of a corresponding unconstrained model in which the correlation between the constructs was set free (Anderson \& Gerbing, 1988).

We also checked for the presence of common source bias. First, we applied Harman's one-factor test (Podsakoff \& Organ, 1986) and an exploratory factor analysis to determine if one factor accounts for a majority of the total variance in the data. The first extracted factor explained only 23 per cent of the total variance, which suggested no common source bias. Second, we undertook a confirmatory factor analysis to compare the fit of a one-factor model, in which the items of the five focal constructs loaded on one construct, with the fit of the five-factor model. The one-factor model offered significantly worse fit $\left(X^{2}{ }_{(14)}=561.57, p<.001\right)$, which further diminished concerns of common source bias (Lattin, Carroll, \& Green, 2003). Conceptually, this bias also tends to be significantly less likely for models that include multiple moderating effects, because participants cannot anticipate the hypothesized relationships or adjust their responses to what they might believe are "appropriate" responses (Simons \& Peterson, 2000).

\section{4 | RESULTS}

Table 1 reports the zero-order correlations and descriptive statistics, and Table 2 provides the hierarchical regression results. Model 1 included the control variables, and then Model 2 added resilience and the three moderators: work overload, organizational rigidity and organizational politics. Models 3-5 added the resilience $\times$ work overload, resilience $\times$ organizational rigidity, and resilience $\times$ organizational politics interaction terms, respectively. Previous research suggests including multiple interaction terms in different regression equations, because their simultaneous inclusion in one model could mask their true moderating effects (Covin, Green, \& Slevin, 2006; De Clercq et al., 2017; Zahra \& Hayton, 2008). Yet to check the invigorating 
TABLE 1 Correlations and descriptive statistics

\begin{tabular}{|c|c|c|c|c|c|c|c|}
\hline & 1 & 2 & 3 & 4 & 5 & 6 & 7 \\
\hline \multicolumn{8}{|c|}{ 1. Disruptive creative behaviour } \\
\hline 2. Resilience & $.342^{* *}$ & & & & & & \\
\hline 4. Organizational rigidity & $-.160^{* *}$ & $.121^{*}$ & $.175^{* *}$ & & & & \\
\hline 5. Organizational politics & -.005 & $.160^{* *}$ & $.272^{* *}$ & $.336^{* *}$ & & & \\
\hline 7. Organizational tenure & -.029 & -.050 & -.053 & $-.303^{* *}$ & $-.187^{* *}$ & .072 & \\
\hline Mean & 5.675 & 5.070 & 3.678 & 3.687 & 3.966 & .438 & 17.465 \\
\hline Standard deviation & .969 & 1.014 & 1.342 & 1.583 & 1.406 & .497 & 9.401 \\
\hline
\end{tabular}

Note: $N=330$.

${ }^{* *} p<.01 ;{ }^{*} p<.05$.

TABLE 2 Regression results (dependent variable: disruptive creative behaviour)

\begin{tabular}{|c|c|c|c|c|c|c|}
\hline & Model 1 & Model 2 & Model 3 & Model 4 & Model 5 & Model 6 \\
\hline Gender ( 1 = Female) & -.113 & -.143 & -.135 & -.129 & -.151 & -.133 \\
\hline Organizational tenure & -.003 & -.007 & -.008 & -.007 & -.008 & -.008 \\
\hline Work overload & & .015 & .000 & .013 & .010 & .004 \\
\hline Organizational rigidity & & $-.133^{* * *}$ & $-.135^{* * *}$ & $-.154^{* * *}$ & $-.130^{* * *}$ & $-.149^{* * *}$ \\
\hline H2: Resilience $\times$ Work overload & & & $.075^{*}$ & & & .031 \\
\hline H3a: Resilience $\times$ Organizational rigidity & & & & $.109^{* * *}$ & & $.086^{* *}$ \\
\hline H3b: Resilience $\times$ Organizational politics & & & & & $.092^{* *}$ & .054 \\
\hline$R^{2}$ & .004 & .164 & .175 & .194 & .181 & .202 \\
\hline
\end{tabular}

Notes: $N=330$; unstandardized coefficients (two-tailed $p$-values).

${ }^{* * *} p<.001 ;{ }^{* *} p<.01 ;{ }^{*} p<.05$.

effects of the three moderators comprehensively, Model 6 included all three interaction terms simultaneously. As recommended by Aiken and West (1991), we mean-centred the product terms before calculating the interaction terms in Models 3-6.

In support of our baseline Hypothesis 1 that personal energy derived from the ability to recover and learn from setbacks spurs the generation of radically new ideas, Model 1 indicated that resilience related positively to disruptive creative behaviour $(\beta=.342$, $p$ <.001). In findings of effects that fall outside the scope of our proposed conceptual framework, Model 2 also indicated a direct negative relationship between organizational rigidity $(\beta=-.133, p<.001)$ and disruptive creative behaviour, though not for work overload ( $\beta=.015, n s)$ or organizational politics ( $\beta=-.010, n s$ ).

Models 3-5 indicated invigorating effects of the three adverse work conditions on the relationship between resilience and disruptive creative behaviour. In particular, the relationship between resilience and disruptive creative behaviour was stronger at higher levels of work overload $(\beta=.075, p<.05)$, organizational rigidity $(\beta=.109$, $p<.001)$ and organizational politics $(\beta=.092, p<.01)$, in support of Hypotheses 2 , and $3 \mathrm{a}$ and $3 \mathrm{~b}$, respectively. The interaction plots in Figure 2 for work overload, and Figures 3(a) and 3(b) for organizational rigidity and organizational politics, depict these interactions graphically. Overall, the results confirm the theoretical prediction that the allocation of discretionary energy derived from resilience to the generation of radically new ideas is higher when this energy allocation is perceived as more valuable as a means to address or undo adverse work circumstances.

The results in Model 6 indicated that the moderating effects of work overload and organizational politics disappeared when considered together with the corresponding moderating effect of organizational rigidity. Among the three contingent factors, an organizational climate that stifles change appears to exert the strongest motivation for employees to leverage their resilience in the form of disruptive creative behaviours, which can help undo this unfavourable aspect of their organization's internal functioning. The concurrent estimation of multiple interaction terms in the same model can obscure the 


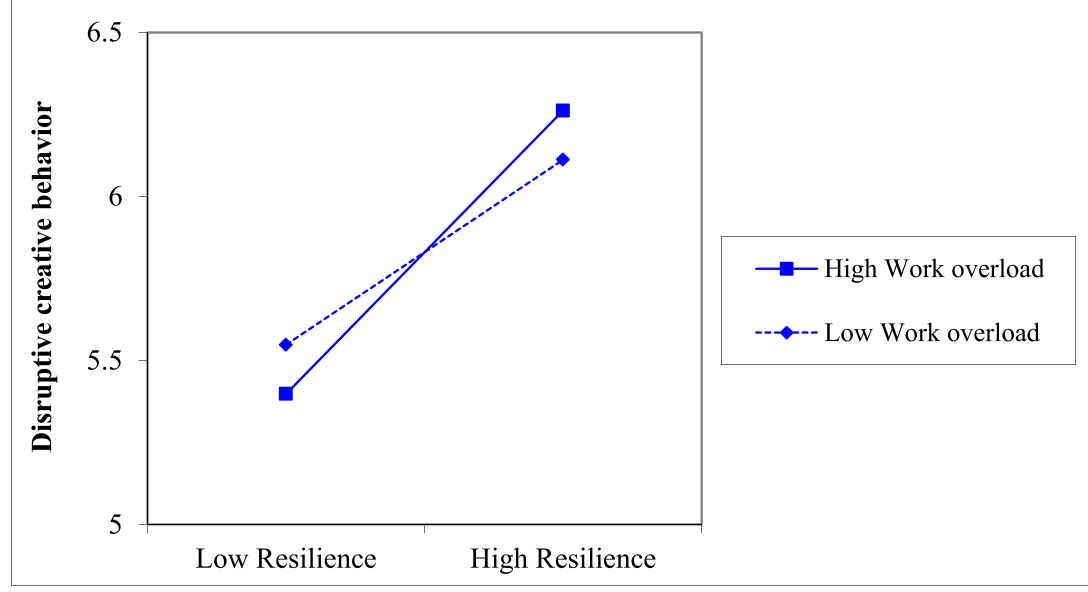

(a) Moderating effect of organizational rigidity on the relationship between resilience and disruptive creative behavior

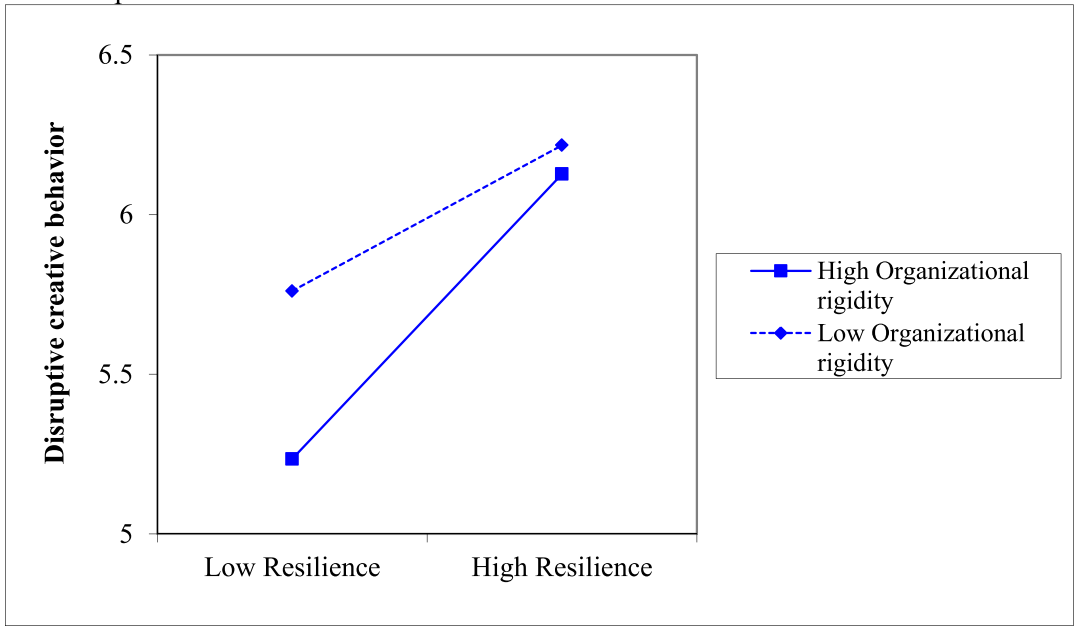

(b) Moderating effect of organizational politics on the relationship between resilience and disruptive creative behavior

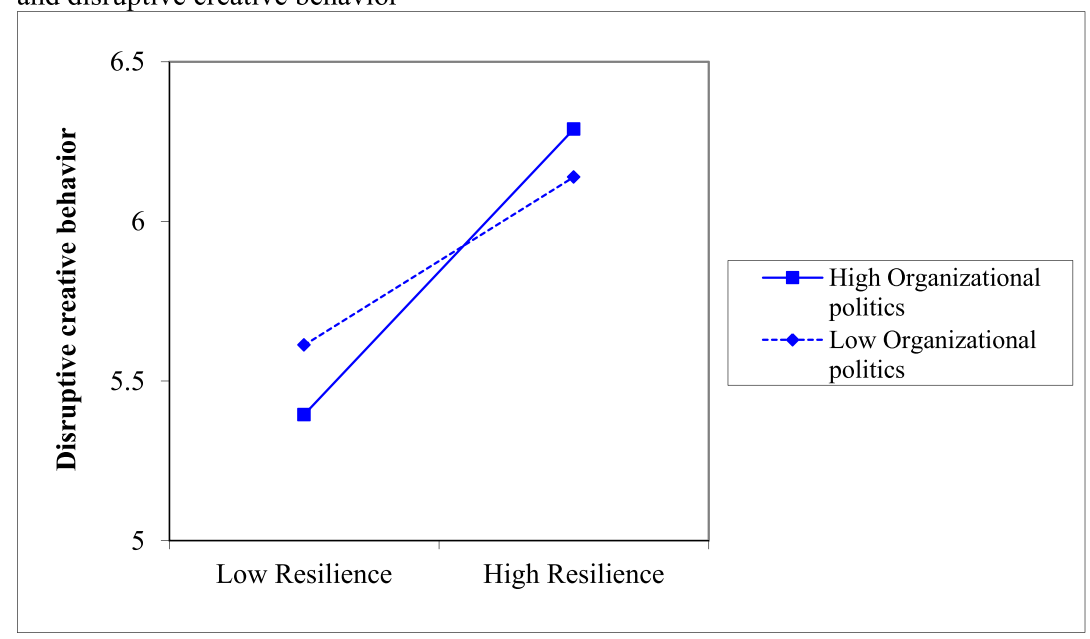

FIGURE 2 Moderating effect of work overload on the relationship between resilience and disruptive creative behaviour [Colour figure can be viewed at wileyonlinelibrary.com]
FIGURE 3 (a) Moderating effect of organizational rigidity on the relationship between resilience and disruptive creative behaviour. (b) Moderating effect of organizational politics on the relationship between resilience and disruptive creative behaviour [Colour figure can be viewed at wileyonlinelibrary.com] identification of true moderating effects though, due to the complex combination of multiple factors (Aiken \& West, 1991; Lattin et al., 2003), so this interpretation warrants great caution. Notably, previous research also indicates that a full model, such as Model 6, in which the signs of the interaction terms match those obtained when adding the interaction terms in separate questions provides evidence for the robustness of the results (Covin et al., 2006; De Clercq, Dimov, \& Thongpapanl, 2010), as in this study. ${ }^{1}$ 
Finally, even if the theoretical focus of this study is on the concurrent interplay of employees' resilience and different resource-draining work conditions for explaining disruptive creative behaviour, we also performed a post hoc analysis to account for possible causal relationships among these variables, in light of findings that employees' resilience levels might depend on their surrounding organizational environment (Kuntz, Malinen, \& Näswall, 2017; Todt, Weiss, \& Hoegl, 2018). In particular, we ran different path models, corresponding with the regression models in Table 2, to estimate the covariances among resilience and the three adverse work conditions (work overload, organizational rigidity and organizational politics). The signs and significance levels of the hypothesized relationships remain completely consistent. Thus, the direct positive relationship between employees' resilience and disruptive creative behaviour, as well as the invigorating effects of the three contingent factors, are robust to possible causal interferences among these constructs (Lattin et al., 2003).

\section{5 | DISCUSSION}

This study contributes to extant creativity research by detailing how employees' resilience levels might spur their propensity to generate radically new ideas for organizational improvement, informed by the reality that these disruptive creative behaviours often elicit negative responses and resistance (Deichmann \& van den Ende, 2014; van Dijk $\&$ van Dick, 2009). The relative lack of attention to these links is somewhat surprising, because the ability to bounce back and learn from workplace adversity, as informed by resilience, can instil employees with the discretionary energy resources needed to engage in resource-enhancing yet controversial work behaviours (Quinn et al., 2012; Youssef \& Luthans, 2007). Consistent with the logic of COR theory (Hobfoll, 2001; Hobfoll \& Shirom, 2000), we investigate the personal resource of resilience as a potentially powerful enabler of disruptive creative behaviours, especially to the extent that employees suffer from adverse, resource-draining work conditions, marked by excessive workloads and unfavourable organizational decision making. Our findings indicate support for the hypothesized relationships.

In particular, we confirm a positive relationship between employees' resilience and their disruptive creative behaviour. Developing disruptive ideas and solutions that address organizational problems can generate resource gains for employees, because these behaviours can stimulate their personal reputation and career development (Gong et al., 2009; Seibert et al., 2001), as well as generate a sense of personal meaningfulness or fulfilment (Kim et al., 2009). Yet employees might not possess the energy needed to bring their radical ideas into the open, especially if they fear that those ideas will be opposed or sabotaged by organizational members who feel threatened by them (Deichmann \& van den Ende, 2014; Yuan \& Woodman, 2010). This challenge diminishes when employees can draw on residual energy that allows them to overcome the hurdles, such as when they possess high resilience levels (Stephens et al., 2013). Consistent with COR theory, employees who possess a strong personal drive to learn from workplace challenges and are able to bounce back from them persistently allocate their personal energy to generate resource-enhancing, radically new ideas, irrespective of the criticism or rejections they might confront in the process (Boon \& Kalshoven, 2014; Hobfoll \& Shirom, 2000). Employees who are equipped with high resilience levels and see challenges as opportunities to learn also may derive personal joy from undertaking these disruptive activities (Meneghel, Borgogni, et al., 2016).

The positive relationship between employees' resilience and disruptive creative behaviour also gets invigorated when employees believe that the resource gains that can arise with this behaviour might protect them against the hardships caused by adverse work conditions. We conceptualized these hardships as manifest in the presence of excessive workloads (Russ-Eft, 2001) and adverse decision making in the form of strict rigidity (Fischer et al., 2014) or dysfunctional politics (Abbas et al., 2014)-workplace features that compromise the quality of employees' organizational functioning. The invigorating effects of these adverse work conditions also follow the logic of COR theory: The expected value of relevant personal resources for generating additional resource gains increases in the presence of resource-depleting circumstances (Hobfoll \& Shirom, 2000). When employees cannot handle their workloads or believe that the organizational climate is overly rigid or political, it becomes more important for them to channel their discretionary energy, derived from their resilience, into disruptive activities that counter and resolve the workplace adversity. That is, the resource gains that employees hope to achieve from leveraging their resilience into possibly controversial, radical ideas are particularly valuable when the implementation of these ideas can help undo the harmful outcomes of unrealistic deadlines, strict organizational resistance to personal initiative, or an organizational climate marked by selfishness and favouritism.

Our study's explicit focus is on the triggering effect of adverse work conditions in channelling employees' resilience toward the generation of radically new ideas. The findings accordingly provide organizations with a more complete understanding of the boundary conditions in which the discretionary energy that originates from high resilience levels is most likely to evoke radically new solutions for improving the status quo. In particular, the confrontation with workplace adversity serves as a catalyst, motivating employees to do something useful with their resilience levels. With this novel and somewhat counterintuitive insight, this study complements research about the direct impact of adverse work conditions in steering employees away from positive work behaviours (e.g., Chen et al., 2015; Jam et al., 2017). Moreover, by affirming the hypothesized invigorating effects, we extend previous research that has focused on how supportive organizational situations might spur employees' subsequent resilience levels (e.g., Kuntz et al., 2017; Todt et al., 2018), as well as their personal initiative and innovative behaviour (Hong, Liao, Raub, \& Han, 2016; Scott \& Bruce, 1994). We focus instead on the concurrent influence of employees' resilience levels and different sources of workplace adversity on their disruptive creative behaviour. Even if the three sources of workplace adversity deplete employees' resources, and thus diminish their ability to devote valuable personal energy to positive work behaviours (Quinn et al., 2012), this mechanism seemingly is 
outweighed by their enhanced motivation to protect themselves against resource depletion (De Clercq \& Belausteguigoitia, 2017b). Thus, the personal resource of resilience spurs disruptive, creative behaviour more forcefully to the extent that employees are surrounded by negative work conditions marked by excessive workloads or dysfunctional decision-making processes, which generate a greater need for such behaviour (Hobfoll, 2001).

In an empirical sense, this issue comes to the fore in the depiction of the slope differences across varying levels of the sources of workplace adversity. The interaction graphs in Figures 2 and 3 indicate that increasing levels of resilience enhance disruptive creative behaviour to a greater extent when employees are unhappy with their workloads, believe their organization is not open to personal initiatives, and believe that it embraces dysfunctional political games. This study thus extends previous research into the direct effects of exposure to unfavourable work conditions on creative behaviours (Chen et al., 2015; Jam et al., 2017; Scott \& Bruce, 1994) and elucidates their triggering roles. Resilience is more likely to be leveraged to support disruptive creative behaviour when employees feel compelled to protect themselves against resource-draining conditions that undermine their organizational functioning.

Overall, the findings offer a more comprehensive understanding of how radically new ideas arise in organizations. That is, a critical but understudied manifestation of creative behaviour is the effort devoted to developing radically new ideas, which may include ideas about completely new work methods or practices, as well as disruptive solutions to specific organizational failures (Frishammar et al., 2016; Seeck \& Diehl, 2017). Such disruptive, creative behaviour tends to be controversial, because it can undermine others' comfort zones and personal privileges (Deichmann \& van den Ende, 2014). Our findings contribute to previous research by detailing the concurrent effects of employees' resilience levels and two types of work adversity (work overload and unfavourable decision making) on the emergence of radically new ideas. It particularly reveals the catalytic role of these adverse conditions in stimulating employees to apply their personal energy, stemming from their resilience, into work activities that might upset the status quo.

\section{1 | Limitations and research directions}

This study has some weaknesses, which offer opportunities for further research. First, some caution is warranted with respect to the possibility of reverse causality; the challenges that employees encounter when seeking to convince other members of the value of their radically new ideas might increase their ability to cope with and recover from difficult work situations (Amabile, 1996). The theorized positive relationship between employees' resilience and disruptive creative behaviour is anchored in COR theory (Hobfoll, 1989, 2001), yet further studies still might apply longitudinal designs to explicate the causal processes that connect this personal resource with enhanced disruptive creative behaviour. In a related vein, we theorized both ability and motivational mechanisms of the positive relationship between resilience and championing behaviour (i.e., employees' ability to cope with anticipated resistance to their disruptive ideas and their motivational expectation of personal satisfaction due to learning). We call for additional research to assess these mechanisms directly and investigate, for example, whether ability or motivation arguments dominate in explaining employees' disruptive creative behaviours in the presence of high resilience levels.

Second, we investigated the role of three contingency factors, to derive an encompassing view of how different sources of workplace adversity-stemming from either their job task environment (work overload) or the nature of organizational decision making (organizational rigidity and organizational politics) -might activate employees to apply discretionary personal energy, derived from their resilience, to generate radically new ideas. However, researchers could detail the influence of other sources of workplace adversity too, in that employees might feel compelled to leverage their resilience as enhanced disruptive creative activities to the extent that they suffer from unclear or ambiguous job descriptions (Eatough, Chang, Miloslavic, \& Johnson, 2011), are exposed to destructive leadership styles (Krasikova, Green, \& LeBreton, 2014) or believe that they operate in unsafe work circumstances that compromise their physical integrity (Hayes, Perander, Smecko, \& Trask, 1998). In a similar vein, the relatively small magnitude of the moderated effects, and the finding that only one of the three adverse work conditions (organizational rigidity) had a direct significant relationship with disruptive creative behaviour, together indicate that our models might be underspecified and suppress some true effects. Continued research should include additional pertinent predictors of creative behaviour, to avoid such potential suppression.

Third, our empirical research context is Angola. Our theoretical arguments are country-neutral, but it is possible that cultural aspects could interfere with the tested conceptual model. On the one hand, Angola scores low on the individualism dimension (Hofstede, Hofstede, \& Minkov, 2010); employees, even those with high resilience levels, therefore might be somewhat hesitant to engage in disruptive work behaviours that make them stand out from their peers. This study accordingly provides a conservative test of the positive connection between resilience and disruptive creative behaviour. On the other hand, Angola is marked by relatively high levels of uncertainty avoidance (Hofstede et al., 2010), such that employees might be particularly eager to leverage their resilience into productive work activities that help mitigate the uncertainties stemming from adverse work conditions. Thus, the invigorating role of the studied sources of resource-draining workplace adversity for connecting resilience to enhanced creativity behaviour might be particularly salient in cultures that seek to avoid risk (Hobfoll \& Shirom, 2000). Further studies could unpack the distinct and combined roles of different cultural values in linking employees' resilience levels to disruptive creative behaviours, through comparative cross-country studies.

\section{2 | Practical implications}

This study has pertinent implications for managerial practice. Organizational decision makers should recognize that employees' resilience 
levels can stimulate their propensity to generate radically new ideas for organizational improvement, and this positive influence is particularly prominent when employees believe that they operate in unfavourable work environments that undermine the quality of their organizational functioning. When employees are willing to generate disruptive solutions to organizational problems, their organizations can benefit, but substantial hurdles also might keep employees from performing such productive behaviours. In particular, they might be concerned about the potential opposition or resistance evoked by their radical ideas, which might threaten their individual standing or reputation among their peers (Deichmann \& van den Ende, 2014; Yuan \& Woodman, 2010).

Employees' residual energy, derived from higher resilience levels, can help overcome this challenge. This study accordingly indicates that organizations might greatly benefit from hiring and retaining employees who recover readily from setbacks and are motivated to learn from such processes. This personal resource of resilience also can be developed and honed (Luthans, Avey, Avolio, \& Peterson, 2010). Managers can boost employees' resilience levels by training them to prepare for negative reactions to their disruptive work activities, as well as to come up with solutions that mitigate the chances that others' reactions compromise their current work situation. Along with such training efforts, organizational decision makers could emphasize how the generation of radically new ideas for organizational improvement can improve employees' personal and career development (Gong et al., 2009; Parboteeah et al., 2015).

Finally, the positive, invigorating interactions between employees' resilience levels and exposure to adverse work conditions indicate that organizations can reap the greatest benefits from stimulating resilient employees to apply their residual energy to productive but disruptive activities, to the extent that the organization's own internal functioning is marked by (1) excessive time pressures that create significant problems with the pace of work and (2) negative decision-making dynamics that stifle personal initiative or embrace self-serving behaviours. To the extent that employees suffer from work overload, organizational rigidity, and organizational politics, specific training initiatives that stimulate them to leverage their personal energy to perform disruptive creative activities should be particularly useful. Ultimately, organizations in which employees struggle with extreme time pressures, resistance to personal initiatives or behind-the-scenes decision making still can thrive, as long as their employee bases are motivated to leverage their personal resources to find radically new ideas for organizational betterment.

\section{6 | CONCLUSION}

This study has investigated how and when employees' resilience is more likely to spur their propensity to generate radically new ideas for organizational improvement. This personal resource fuels disruptive creative behaviour, especially when employees face significant adversity in their organizational environment, due to excessive workloads or negative decision-making dynamics. We hope this research establishes a platform for continued studies into how organizations might leverage pertinent employee resources into productive work behaviours, particularly in the presence of significant workplace adversity.

\section{ENDNOTE}

${ }^{1}$ Only one of the three moderating effects was significant in Model 6, which might reflect different interpretations of the two-way interaction term effects (which include mean-centred variables) in Model 6, relative to Models 3-5. That is, each of the two-way interaction terms in Model 6 captures a differential effect of resilience on disruptive creative behaviour at non-average values of a specific moderator (work overload, organizational politics and organizational rigidity), but their simultaneous estimation in the presence of the other two-way interactions in that same model means that the effect of each focal moderator is evaluated only in a space that captures the average values of the other moderators (Aiken \& West, 1991). For example, the moderating effect of work overload in Model 6 reflects a scenario in which both organizational rigidity and organizational politics, mean-centred in their respective interaction terms, operate at their average values. In contrast, the moderating effect of work overload in Model 3 covers the entire set of values for organizational politics and organizational rigidity. The absence of significant moderating effects in Model 6 for two of the three moderators thus indicates that a particular moderating effect might be influenced by the effects of the other moderators (De Clercq et al., 2010). Continued research might use configurational perspectives to investigate the extent to which employees' exposure to the "least ideal" configuration-high levels of work overload, organizational politics and organizational rigidity-might trigger employees' efforts to leverage their resilience as disruptive creative behaviours (Doty, Glick, \& Huber, 1993; Vorhies \& Morgan, 2003).

\section{ORCID}

Dirk De Clerca (10) https://orcid.org/0000-0003-1476-2965

\section{REFERENCES}

Abbas, M., Raja, U., Darr, W., \& Bouckenooghe, D. (2014). Combined effects of perceived politics and psychological capital on job satisfaction, turnover intentions, and performance. Journal of Management, 40, 1813-1830. https://doi.org/10.1177/0149206312455243

Acikgoz, A., \& Gunsel, A. (2016). Individual creativity and team climate in software development projects: The mediating role of team decision processes. Creativity and Innovation Management, 25, 445-463. https://doi.org/10.1111/caim.12173

Aiken, L. S., \& West, S. G. (1991). Multiple regression: Testing and interpreting interactions. Newbury Park, CA: Sage.

Altaf, A., \& Awan, M. A. (2011). Moderating effect of workplace spirituality on the relationship of job overload and job satisfaction. Journal of Business Ethics, 104, 93-99. https://doi.org/10.1007/s10551-011-0891-0

Amabile, T. M. (1996). Creativity in context. Boulder, CO: Westview.

Anderson, J. C., \& Gerbing, D. W. (1988). Structural equation modeling in practice: A review and recommended two-step approach. Psychology Bulletin, 103, 411-423. https://doi.org/10.1037/00332909.103.3.411

Avery, D. R., Tonidandel, S., Volpone, S. D., \& Raghuram, A. (2010). Overworked in America? How work hours, immigrant status, and interpersonal justice affect perceived work overload. Journal of Managerial Psychology, 25, 133-147. https://doi.org/10.1108/ 02683941011019348

Baer, J., \& Kaufman, J. C. (2008). Gender differences in creativity. Journal of Creative Behavior, 42, 75-105. https://doi.org/10.1002/j.21626057.2008.tb01289.x 
Bardoel, E. A., Pettit, T. M., De Cieri, H., \& McMillan, L. (2014). Employee resilience: An emerging challenge for HRM. Asia Pacific Journal of Human Resources, 52, 279-297. https://doi.org/10.1111/17447941.12033

Boehlke, S. (2008). The Politics of Creativity ${ }^{\mathrm{TM}}$ : Four domains for inquiry and action by leaders in R\&D. Creativity and Innovation Management, 17, 77-87. https://doi.org/10.1111/j.1467-8691.2007.00470.x

Boon, C., \& Kalshoven, K. (2014). How high-commitment HRM relates to engagement and commitment: The moderating role of task proficiency. Human Resource Management, 53, 403-420. https://doi.org/10.1002/ hrm.21569

Bos-Nehles, A., Bondarouk, T., \& Nijenhuis, K. (2017). Innovative work behaviour in knowledge-intensive public sector organizations: The case of supervisors in the Netherlands fire services. International Journal of Human Resource Management, 28, 379-398. https://doi.org/10.1080/ 09585192.2016 .1244894

Brislin, R. W., Lonner, W., \& Thorndike, R. M. (1973). Cross-cultural research methods. New York: John Wiley \& Sons.

Buchanan, D., \& Badham, R. (1999). Politics and organizational change: The lived experience. Human Relations, 52, 609-629. https://doi.org/ 10.1177/001872679905200503

Caniëls, M. C. J., \& Baaten, S. M. J. (2019). How a learning-oriented organizational climate is linked to different proactive behaviors: The role of employee resilience. Social Indicators Research, 143, 561-577. https://doi.org/10.1007/s11205-018-1996-y

Carmeli, A., \& Spreitzer, G. M. (2009). Trust, connectivity, and thriving: Implications for innovative behaviors at work. Journal of Creative Behavior, 43, 169-191. https://doi.org/10.1002/j.2162-6057.2009. tb01313.x

Chang, C.-H., Rosen, C. C., \& Levy, P. E. (2009). The relationship between perceptions of organizational politics and employee attitudes, strain, and behavior: A meta-analytic examination. Academy of Management Journal, 52, 779-801. https://doi.org/10.5465/amj.2009.43670894

Chen, M. H., Chang, Y. Y., \& Chang, Y. C. (2015). Exploring individual-work context fit in affecting employee creativity in technology-based companies. Technological Forecasting and Social Change, 98, 1-12. https:// doi.org/10.1016/j.techfore.2015.05.002

Cho, I., Park, H., \& Dahlgaard-Park, S. M. (2017). The impacts of organisational justice and psychological resilience on employee commitment to change in an M\&A context. Total Quality Management \& Business Excellence, 28, 989-1002. https://doi.org/10.1080/ 14783363.2017.1303890

Conley, K. M., Clark, M. A., Vande Griek, O. H., \& Mancini, J. A. (2016). Looking backward, moving forward: Exploring theoretical foundations for understanding employee resilience. Industrial and Organizational Psychology, 9, 491-497. https://doi.org/10.1017/iop.2016.45

Conway, J. M., \& Lance, C. E. (2010). What reviewers should expect from authors regarding common method bias in organizational research. Journal of Business Psychology, 25, 325-334. https://doi.org/10.1007/ s10869-010-9181-6

Covin, J. G., Green, K. M., \& Slevin, D. P. (2006). Strategic process effects on the entrepreneurial orientation-sales growth rate relationship. Entrepreneurship Theory \& Practice, 30, 57-81. https://doi.org/ 10.1111/j.1540-6520.2006.00110.x

Crawford, E. R., LePine, J. A., \& Rich, B. L. (2010). Linking job demands and resources to employee engagement and burnout: $A$ theoretical extension and meta-analytic test. Journal of Applied Psychology, 93, 834-848. https://doi.org/10.1037/a0019364

De Clercq, D., \& Belausteguigoitia, I. (2017a). Mitigating the negative effect of perceived organizational politics on organizational citizenship behavior: Moderating roles of contextual and personal resources.
Journal of Management and Organization, 23, 689-708. https://doi. org/10.1017/jmo.2017.7

De Clercq, D., \& Belausteguigoitia, I. (2017b). The relationship between tenacity and knowledge exchange in a Mexican organization: Moderating effects of within-work and work-family role conflict. Journal of Leadership \& Organizational Studies, 24, 246-260. https://doi.org/ 10.1177/1548051816664680

De Clercq, D., Castañer, X., \& Belausteguigoitia, I. (2011). Entrepreneurial initiative selling within organizations: Towards a more comprehensive motivational framework. Journal of Management Studies, 48, 1269-1290. https://doi.org/10.1111/j.1467-6486.2010.00999.x

De Clercq, D., Dimov, D., \& Thongpapanl, N. (2010). The moderating impact of internal social exchange processes on the entrepreneurial orientation-performance relationship. Journal of Business Venturing, 25, 87-103. https://doi.org/10.1016/j.jbusvent.2009.01.004

De Clercq, D., Rahman, Z. M., \& Belausteguigoitia, I. (2017). Task conflict and employee creativity: The critical roles of learning orientation and goal congruence. Human Resource Management, 56, 93-109. https:// doi.org/10.1002/hrm.21761

Deichmann, D., \& van den Ende, J. (2014). Rising from failure and learning from success: The role of past experience in radical initiative taking. Organization Science, 25, 670-690. https://doi.org/10.1287/ orsc. 2013.0870

Doty, D. H., Glick, W. H., \& Huber, G. P. (1993). Fit, effectiveness, and equifinality: A test of two configurational theories. Academy of Management Journal, 36, 1196-1250. https://doi.org/10.2307/256810

Eatough, E. M., Chang, C. H., Miloslavic, S. A., \& Johnson, R. E. (2011). Relationships of role stressors with organizational citizenship behavior: A meta-analysis. Journal of Applied Psychology, 96, 619-632. https:// doi.org/10.1037/a0021887

Farmer, S. M., Tierney, P., \& Kung-McIntyre, K. (2003). Employee creativity in Taiwan: An application of role identity theory. Academy of Management Journal, 46, 618-630. https://doi.org/10.2307/30040653

Fischer, S., Frese, M., Mertins, J. C., Hardt, J. V., Flock, T., Schauder, J., ... Wiegel, J. (2014). Climate for personal initiative and radical and incremental innovation in firms: A validation study. Journal of Enterprising Culture, 22, 91-109. https://doi.org/10.1142/ S0218495814500046

Frishammar, J., Dahlskog, E., Krumlinde, C., \& Yazgan, K. (2016). The front end of radical innovation: A case study of idea and concept development at Prime Group. Creativity and Innovation Management, 25, 179-198. https://doi.org/10.1111/caim.12175

George, J. M., \& Zhou, J. (2001). When openness to experience and conscientiousness are related to creative behavior: An interactional approach. Journal of Applied Psychology, 86, 513-524. https://doi.org/10.1037/ 0021-9010.86.3.513

Gerbing, D. W., \& Anderson, J. C. (1988). An updated paradigm for scale development incorporating unidimensionality and its assessment. Journal of Marketing Research, 25, 186-192. https://doi.org/10.1177/ 002224378802500207

Gong, Y., Huang, J.-C., \& Farh, J.-L. (2009). Employee learning orientation, transformational leadership, and employee creativity: The mediating role of employee creative self-efficacy. Academy of Management Journal, 52, 765-778. https://doi.org/10.5465/amj.2009.43670890

Hayes, B. E., Perander, J., Smecko, T., \& Trask, J. (1998). Measuring perceptions of workplace safety: Development and validation of the work safety scale. Journal of Safety Research, 29, 145-161. https://doi.org/ 10.1016/S0022-4375(98)00011-5

Hobfoll, S. E. (1989). Conservation of resources: A new attempt at conceptualizing stress. American Psychologist, 44, 513-524. https://doi.org/ 10.1037/0003-066X.44.3.513 
Hobfoll, S. E. (2001). The influence of culture, community, and the nestedself in the stress process: Advancing conservation of resource theory. Applied Psychology: An International Review, 50, 337-369. https://doi. org/10.1111/1464-0597.00062

Hobfoll, S. E., \& Shirom, A. (2000). Conservation of resources theory: Applications to stress and management in the workplace. In R. T. Golembiewski (Ed.), Handbook of organization behavior (2nd ed.) (pp. 57-81). New York: Marcel Dekker.

Hochwarter, W. A., Kacmar, C., Perrewé, P. L., \& Johnson, D. (2003). Perceived organizational support as a mediator of the relationship between politics perceptions and work outcomes. Journal of Vocational Behavior, 63, 438-456. https://doi.org/10.1016/S00018791(02)00048-9

Hofstede, G. H., Hofstede, G. J., \& Minkov, M. (2010). Cultures and organizations: Software of the mind. Intercultural cooperation and its importance for survival (3rd ed.). New York: McGraw-Hill.

Hong, Y., Liao, H., Raub, S., \& Han, J. (2016). What it takes to get proactive: An integrative multilevel model of the antecedents of personal initiative. Journal of Applied Psychology, 10, 687-701. https://doi.org/ 10.1037/apl0000064

Jam, F., Donia, M. B. L., Raja, U., \& Ling, C. H. (2017). A time-lagged study on the moderating role of overall satisfaction in perceived politics: Job outcomes relationships. Journal of Management and Organization, 23 , 321-336. https://doi.org/10.1017/jmo.2016.13

Janssen, O. (2001). Fairness perceptions as a moderator in the curvilinear relationships between job demands, and job performance and job satisfaction. Academy of Management Journal, 44, 1039-1050. https://doi.org/10.5465/3069447

Jones, D. A. (2009). Getting even with one's supervisor and one's organization: Relationships among types of injustice, desires for revenge, and counterproductive work behaviors. Journal of Organizational Behavior, 30, 525-542. https://doi.org/10.1002/job.563

Kacmar, K. M., \& Baron, R. A. (1999). Organizational politics: The state of the field, links to related processes, and an agenda for future research. In G. Ferris (Ed.), Research in personnel and human resource management. Greenwich, CT: JAI Press.

Kaufman, J. C., \& Baer, J. (2004). Sure, I'm creative-but not in math! Self-reported creativity in diverse domains. Empirical Studies of the Arts, 22, 143-155. https://doi.org/10.2190/26HQ-VHE8-GTLNBJJM

Kim, T.-Y., Hon, A. H., \& Crant, J. M. (2009). Proactive personality, employee creativity, and newcomer outcomes: A longitudinal study. Journal of Business and Psychology, 24, 93-103. https://doi.org/ 10.1007/s10869-009-9094-4

King, D. D., Newman, A., \& Luthans, F. (2016). Not if, but when we need resilience in the workplace. Journal of Organizational Behavior, 37, 782-786. https://doi.org/10.1002/job.2063

Krasikova, D., Green, S. G., \& LeBreton, J. M. (2014). Destructive leadership: A theoretical review, integration, and future research agenda. Journal of Management, 39, 1308-1338. https://doi.org/10.1177/ 0149206312471388

Kuntz, J. C., Malinen, S., \& Näswall, K. (2017). Employee resilience: Directions for resilience development. Consulting Psychology Journal: Practice and Research, 69, 223-242. https://doi.org/10.1037/ cpb0000097

Lattin, J. M., Carroll, J. D., \& Green, P. E. (2003). Analyzing multivariate data. Belmont, CA: Thomson Brooks/Cole.

Liang, J., Farh, C. I. C., \& Farh, J. (2012). Psychological antecedents of promotive and prohibitive voice: A two-wave examination. Academy of Management Journal, 55, 71-92. https://doi.org/10.5465/amj. 2010.0176
Linnenluecke, M. K. (2017). Resilience in business and management research: A review of influential publications and a research agenda. International Journal of Management Reviews, 19, 4-30. https://doi. org/10.1111/ijmr.12076

Luthans, F. (2002). The need for and meaning of positive organizational behavior. Journal of Organizational Behavior, 23, 695-706. https://doi. org/10.1002/job.165

Luthans, F., Avey, J. B., Avolio, B. J., \& Peterson, S. (2010). The development and resulting performance impact of positive psychological capital. Human Resource Development Quarterly, 21, 41-66. https:// doi.org/10.1002/hrdq.20034

Masten, A. S. (2001). Ordinary magic: Resilience process in development. American Psychologist, 56, 227-239. https://doi.org/10.1037/0003066X.56.3.227

Meneghel, I., Borgogni, L., Miraglia, M., Salanova, M., \& Martínez, I. M. (2016). From social context and resilience to performance through job satisfaction: A multilevel study over time. Human Relations, 69, 2047-2067. https://doi.org/10.1177/0018726716631808

Meneghel, I., Salanova, M., \& Martínez, I. M. (2016). Feeling good makes us stronger: How team resilience mediates the effect of positive emotions on team performance. Journal of Happiness Studies, 17, 239-255. https://doi.org/10.1007/s10902-014-9592-6

Milliken, F. J., Morrison, E. W., \& Hewlin, P. (2003). An exploratory study of employee silence: Issues that employees don't communicate upward and why. Journal of Management Studies, 40, 1453-1476. https://doi. org/10.1111/1467-6486.00387

Morrison, E. W. (2011). Employee voice behavior: Integration and directions for future research. Academy of Management Annals, 5, 373-412. https://doi.org/10.5465/19416520.2011.574506

Naranjo-Valencia, J. C., Jimenez-Jimenez, D., \& Sanz-Valle, R. (2017). Organizational culture and radical innovation: Does innovative behavior mediate this relationship? Creativity and Innovation Management, 26, 407-417. https://doi.org/10.1111/caim.12236

Oldham, G. R., \& Cummings, A. (1996). Employee creativity: Personal and contextual factors at work. Academy of Management Journal, 39, 607-634. https://doi.org/10.2307/256657

Paillé, P. (2011). Perceived stressful work, citizenship behaviour and intention to leave the organization in a high turnover environment: Examining the mediating role of job satisfaction. Journal of Management Research, 3, 1-16. https://doi.org/10.5296/jmr.v3i1.487

Parboteeah, K. P., Hoegl, M., \& Muethel, M. (2015). Team characteristics and employees' individual learning: A cross-level investigation. European Management Journal, 33, 287-295. https://doi.org/ 10.1016/j.emj.2015.02.004

Podsakoff, P. M., \& Organ, D. W. (1986). Self-reports in organization research: Problems and prospects. Journal of Management, 12, 532-544. https://doi.org/10.1177/014920638601200408

Pooja, A. A., De Clercq, D., \& Belausteguigoitia, I. (2016). Job stressors and organizational citizenship behavior: The roles of organizational commitment and social interaction. Human Resource Development Quarterly, 27, 373-405. https://doi.org/10.1002/hrdq.21258

Quinn, R. W., Spreitzer, G. M., \& Lam, C. F. (2012). Building a sustainable model of human energy in organizations: Exploring the critical role of resources. Academy of Management Annals, 6, 337-396. https://doi. org/10.5465/19416520.2012.676762

Richtnér, A., \& Löfsten, H. (2014). Managing in turbulence: How the capacity for resilience influences creativity. R\&D Management, 44, 137-151. https://doi.org/10.1111/radm.12050

Russ-Eft, D. (2001). Workload, stress, and human resource development. Human Resource Development Quarterly, 12, 1-3. https://doi.org/ 10.1002/1532-1096(200101/02)12:1<1::AID-HRDQ1>3.0.CO;2-Q 
Scott, S. G., \& Bruce, R. A. (1994). Determinants of innovative behavior: A path model of individual innovation in the workplace. Academy of Management Journal, 37, 580-607. https://doi.org/10.2307/256701

Seeck, H., \& Diehl, M.-R. (2017). A literature review on HRM and innovation-Taking stock and future directions. International Journal of Human Resource Management, 28, 913-944. https://doi.org/10.1080/ 09585192.2016 .1143862

Seibert, S. E., Kraimer, M. L., \& Crant, J. M. (2001). A longitudinal model linking proactive personality and career success. Personnel Psychology, 54, 845-874. https://doi.org/10.1111/j.1744-6570.2001.tb00234.x

Shalley, C. E., Gilson, L. L., \& Blum, T. C. (2009). Interactive effects of growth need strength, work context, and job complexity on selfreported creative performance. Academy of Management Journal, 52, 489-505. https://doi.org/10.5465/amj.2009.41330806

Simons, T., \& Peterson, R. S. (2000). Task conflict and relationship conflict in top management teams: The pivotal role of intragroup trust. Journal of Applied Psychology, 83, 102-111. https://doi.org/10.1037/00219010.85.1.102

Spector, P. E. (2006). Method variance in organizational research: Truth or urban legend? Organizational Research Methods, 9, 221-232. https:// doi.org/10.1177/1094428105284955

Stephens, J. P., Heaphy, E. D., Carmeli, A., Spreitzer, G. M., \& Dutton, J. E. (2013). Relationship quality and virtuousness: Emotional carrying capacity as a source of individual and team resilience. Journal of Applied Behavioral Science, 49, 13-41. https://doi.org/10.1177/ 0021886312471193

Stokes, P., Smith, S., Wall, T., Moore, N., Rowland, C., Ward, T., \& Cronshaw, S. (2018). Resilience and the (micro-)dynamics of organizational ambidexterity: Implications for strategic HRM. International Journal of Human Resource Management, 30, 1287-1322. https://doi. org/10.1080/09585192.2018.1474939

Sutton, R. I., \& Hargadon, A. (1996). Brainstorming groups in context: Effectiveness in a product design firm. Administrative Science Quarterly, 41, 685-718. https://doi.org/10.2307/2393872

Sweetman, D., Luthans, F., Avey, J. B., \& Luthans, B. C. (2011). Relationship between positive psychological capital and creative performance. Canadian Journal of Administrative Sciences, 28, 4-13. https://doi.org/ 10.1002/cjas.175

Tierney, P., \& Farmer, S. M. (2002). Creative self-efficacy: Its potential antecedents and relationship to creative performance. Academy of Management Journal, 45, 1137-1148. https://doi.org/10.5465/ 3069429

Todt, G., Weiss, M., \& Hoegl, M. (2018). Mitigating negative side effects of innovation project terminations: The role of resilience and social support. Journal of Product Innovation Management, 35, 518-542. https:// doi.org/10.1111/jpim.12426

Unsworth, K. L., \& Mason, C. M. (2016). Self-concordance strategies as a necessary condition for self-management. Journal of Occupational and Organizational Psychology, 89, 711-733. https://doi.org/10.1111/ joop.12149

van Dijk, R., \& van Dick, R. (2009). Navigating organizational change: Change leaders, employee resistance and work-based identities. Journal of Change Management, 9, 143-163. https://doi.org/10.1080/ 14697010902879087
Vorhies, D. W., \& Morgan, N. A. (2003). A configuration theory assessment of marketing organization fit with business strategy and its relationship with marketing performance. Journal of Marketing, 67, 100-115. https://doi.org/10.1509/jmkg.67.1.100.18588

Wang, Z., Li, C., \& Li, X. (2017). Resilience, leadership and work engagement: The mediating role of positive affect. Social Indicators Research, 132, 699-708. https://doi.org/10.1007/s11205-016-1306-5

Wolfson, N. E., \& Mulqueen, C. (2016). Advancing employee resilience research: Additional thoughts. Industrial and Organizational Psychology, 9, 452-456. https://doi.org/10.1017/iop.2016.38

Youssef, C. M., \& Luthans, F. (2007). Positive organizational behavior in the workplace. Journal of Management, 33, 774-800. https://doi.org/ 10.1177/0149206307305562

Yuan, F., \& Woodman, R. (2010). Innovative behavior in the workplace: The role of performance and image outcome expectations. Academy of Management Journal, 53, 323-342. https://doi.org/10.5465/ amj.2010.49388995

Zahra, S., \& Hayton, J. C. (2008). The effect of international venturing on firm performance: The moderating influence of absorptive capacity. Journal of Business Venturing, 23, 195-220. https://doi.org/10.1016/j. jbusvent.2007.01.001

Zhou, J., \& George, J. M. (2001). When job dissatisfaction leads to creativity: Encouraging the expression of voice. Academy of Management Journal, 44, 682-696. https://doi.org/10.5465/3069410

Zhou, J., Shin, S. J., \& Cannella, A. A. Jr. (2008). Employee self-perceived creativity after mergers and acquisitions: Interactive effects of threat-opportunity perception, access to resources, and support for creativity. Journal of Applied Behavioral Science, 44, 397-421. https:// doi.org/10.1177/0021886308328010

\section{AUTHOR BIOGRAPHIES}

Dirk De Clercq is Professor of Management in the Goodman School of Business at Brock University, Canada. He is also Research Professor in the Small Business Research Centre at Kingston University, UK. His research interests are in entrepreneurship, organizational behaviour, and cross-country studies.

Renato Pereira is Integrated Researcher in OBSERVARE Research Centre and Guest Professor of Management in ISCTE-IUL, both in Lisbon, Portugal. His research interests are in entrepreneurship, innovation and international management with a particular focus on Africa.

How to cite this article: De Clercq D, Pereira R. Resilient employees are creative employees, when the workplace forces them to be. Creat Innov Manag. 2019;28:329-342. https://doi. org/10.1111/caim.12328 